\title{
Environmental impact of hazardous waste landfill breakdown
}

\author{
M. Kubal, V. Kočí, A. Švagr \& M. Kuraš \\ Department of Environmental Chemistry, \\ Institute of Chemical Technology in Prague, Czech Republic.
}

\begin{abstract}
The subject of the study was a hazardous waste landfill in Pozd'átky (Southern Moravia, Czech Republic), where toxic chemicals started to escape into surrounding area causing significant impact on environment. The source of pollution was waste ferrous sulphate deposited at the landfill in total amount 12000 tons. Because of perforation of bottom linen, as well as destruction of upper coverage HDPE foil, the highly acidic and concentrated leachates ( $\mathrm{pH} 2-3$, $\mathrm{SO}_{4}{ }^{2-}$ up to $45000 \mathrm{mg} / \mathrm{l}$ ) were formed in landfill body and released into groundwater and in some cases even directly flowed on the ground surface. This paper reports the ecotoxicological analysis of the area impacted by landfill breakdown. Three different types of soil ecotoxicological tests were performed using samples taken at the area affected. The main adverse effect observed was caused by low $\mathrm{pH}$. No additional toxic response was obtained after neutralisation.
\end{abstract}

\section{Introduction}

\subsection{Landfill construction and history}

Landfill area in Pozd'átky was opened in 1995 as one of the most modern waste depostion facilities in the Czech Republic. It is situated in the agricultural landscape, six kilometers from the nearest city (Třebić). The landfill storage capacity was mainly designed to deposit municipal waste but there were also high-level safety sectors planned to deposit hazardous wastes, including those from chemical industry. Basically, there were three types of waste to be deposited at the landfill: 1) municipal waste (open-air casette), 2) hazardous waste in steel containers (open-air casette), and 3) high toxic hazardous waste (deposition hall). 


\section{Environmental Health Risk}

When constructing the open-air casette, its bottom part was sealed by 1) a mixture of clay and bentonite forming a layer having $300 \mathrm{~mm}$ thickness, 2) two layers of geotextile (Bentofix, $10 \mathrm{~mm})$, 3) HDPE insulating foil $(2.0 \mathrm{~mm})$, and 4) one layer of protecting geotextile Secutex. The same sealing layers were put to the bottom part of deposition hall. Two independent drainage systems were installed in the landfill. The first one was placed on the above specified sealing layer to remove possible leachates from the deposited waste. The second drainage system was placed into the soil bellow the sealing layer to collect groundwater. The landfill leachates were to be accumulated in the two tanks $\left(2 \times 95 \mathrm{~m}^{3}\right)$ for further processing.

Irrespective of the main purpose of the landfill, as declared in a project approved, almost no municipal waste was deposited during three years of operation (1995 - 98). Instead of loading municipal waste the landfill capacity was mostly used to deposit hazardous waste, which included asbestos, building demolition waste, different tannery wastes, paints, sludge from waste water treatment, drugs and waste catalyzators. In 1996 the open-air casette started to be filled up with waste ferrous sulphate from titanium white production. This waste contained free sulphuric acid in the amount ranging from $10 \%$ to $14 \% \mathrm{w} / \mathrm{w}$. Deposition of ferrous sulphate was approved by the state authorities under condition that the waste would be neutralised and stabilized prior to transferring to the landfill. This condition was, however, not accepted by a company responsible for landfill operation and ferrous sulphate was loaded without any preliminary treatment.

\subsection{Landfill breakdown}

After loading about 12000 tons of waste ferrous sulphate into open-air casette the groundwater quality around the landfill started to lower rapidly. During a short period in 1999 it decreased under acceptable limits and the groundwater contamination became more and more serious. Finally the groundwater bellow landfill showed $\mathrm{pH}$ within $2.7-3.3$, while sulphate content reached values up to $45000 \mathrm{mg} / \mathrm{l}$. Trace amounts of chromium, cadmium, cobalt, and vanadium were detected as well. Hydrogeological tests (monitoring of a tracer) suggested that bottom linen of the landfill was perforated (probably by heavy machinery during waste loading). Through these perforations groundwater was allowed to communicate with the landfill body. Since isolation of ferrous sulphate by upper coverage HDPE foil was not complete, rain water was allowed to penetrate too and highly acidic ferrous sulphate was solubilized and released from the landfill.

When regular monitoring of groundwater quality in the landfill area first indicated possible environmetal impact, the local authorities stopped loading waste to the landfill until groundwater quality returned to the limits demanded by directives. At this time, however, the company responsible for landfill operation declared itself insolvent and rapid solution of the problem became practically impossible. An official receiver started the formal procedures directed to finding a new owner of the landfill, during which time almost no activities were allowed at the landfill area. The situation became paralyzed since 1999 and only limited precautions were taken against spreading contamination. Increasing volume of acidic sulphate leachate in the landfill body caused fatal breakdown in landfill construction in winter 2001 and the concentrated ferrous sulphate solution was relased directly to the ground surface. 


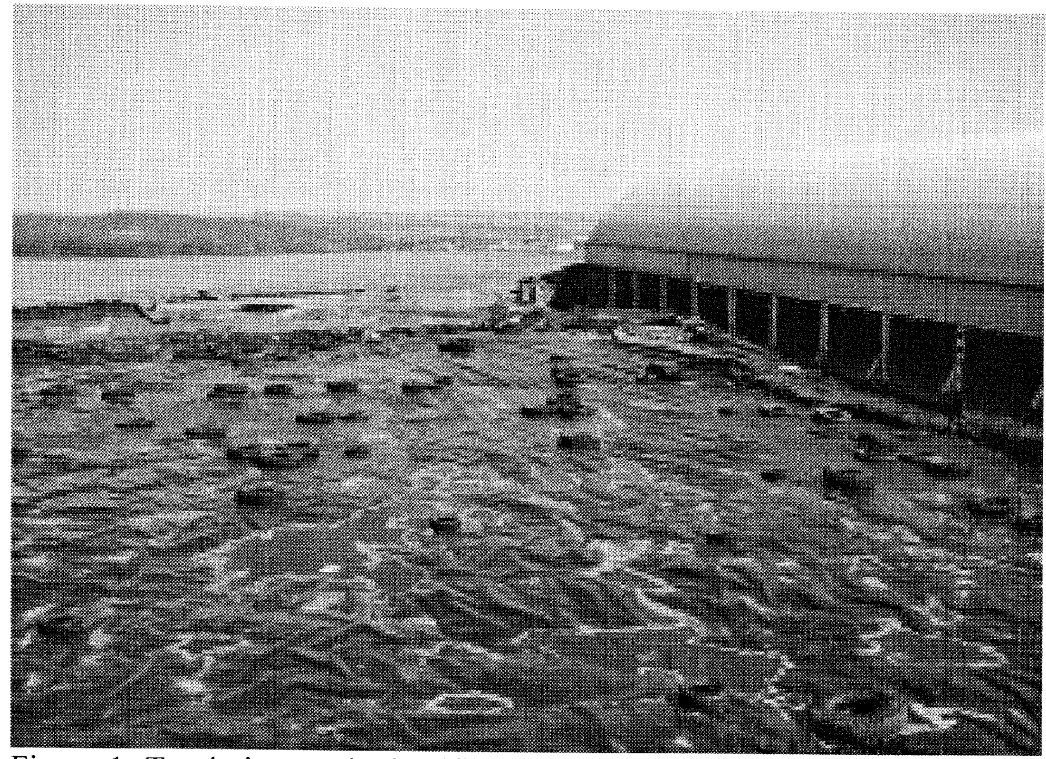

Figure 1: Total view to the landfill (September 1999) with an open-air casette covered by HDPE foil and deposition hall.

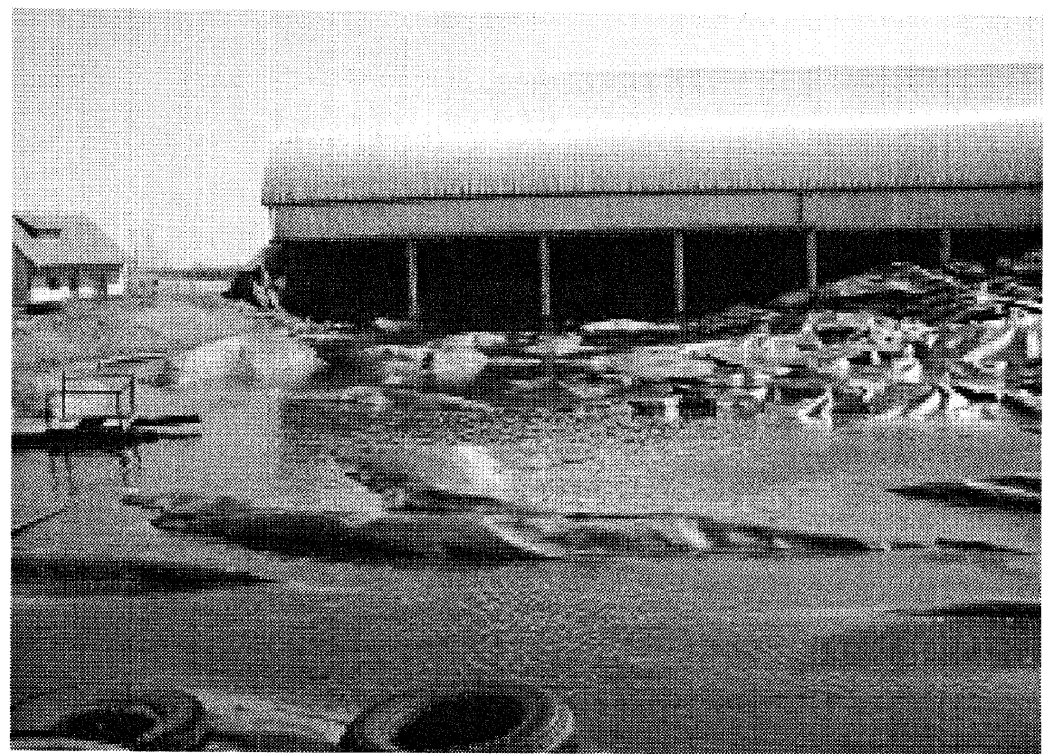

Figure 2: Solubilized ferrous sulphate in the open-air casette (July 2000). 


\section{Environmental Health Risk}

\subsection{Environmetal and health impact}

The contact of ferrous sulphate deposited at the landfill with rainwater and groundwater resulted in serious damage in the surrounding area. Significant decrease in groundwater quality was the first consequence of landfill breakdown. It follows from the Fig. 3 that contamination of groundwater bellow the landfill appeared within a relatively short period April - May 1999. The both groundwater parameters keep practically constant values since then in all monitoring wells around the landfill. This means that landfill body presents permanent source of environmental pollution. It should be noted that both $\mathrm{pH}$ value and ferrous sulphate content measured in groundwater in different monitoring points were influenced by soil neutralization capacity and they were usually significantly different from the values found in the leachate present directly in the landfill body (where $\mathrm{pH}$ was about 1.0, while sulphate concentration reached $100000 \mathrm{mg} / \mathrm{l})$. Since the landfill is situated on sloping land, the polluted groundwater flows downhill and rises from the ground about $100 \mathrm{~m}$ down the landfill. As shown in the Fig. 4 a temporary neutralisation meander was built up close to this point to partly limit the groundwater acidity.

The second - and untill now the most serious damage - followed when acidic leachate was released directly on the ground surface in winter 2001. Several hundreds cubic meters of the leachate came into contact with vegetation at the area of about $10000 \mathrm{~m}^{2}$ causing complete devastation all the life there.

The third environmental impact followed from the fact that the acidic leachate comes (or may come) into contact with other wastes deposited in the landfill forming soluble or gaseous toxic products. As noted above there are many hazardous wastes situated especially in the deposition hall, whose contact with acidic solution could be extremely dangerous. Cyanide containing waste can be mentioned as an example of the waste, which should avoid contacting with acid because of risk of hydrogen cyanide formation. In a similar way the acidic liquid could penetrate into the space, which was used to deposit drugs, batteries and many other toxic materials. From this reason it was decided to pump out (and transport to a treatment facility) a part of the extremely concentrated aqueous phase from the landfill body to keep its level under the limit critical for hydrogen cyanide formation. Approximately $1500 \mathrm{~m}^{3}$ of acidic aqueous phase had to be removed within a period $2000-2001$, which demanded high costs, since special transport means had to be used.

Since the contact of highly acidic leachate with cyanide wastes became practically permanent the monitoring wells were installed in the depostion hall and the samples of air from bottom parts of the hall started to be taken regularly to detect presence of hydrogen cyanide. The air monitoring was perforemd during two years period. Since hydrogen cyanide has never been found in the air samples, it was concluded that cyanide content in the waste deposited was minimized by oxidation.

The aim of this study was to investigate environmental impact of the landfill breakdown by means of three types of ecotoxicological tests. The impact on landfill area was compared with non-affected land. 
Environmental Health Risk 97

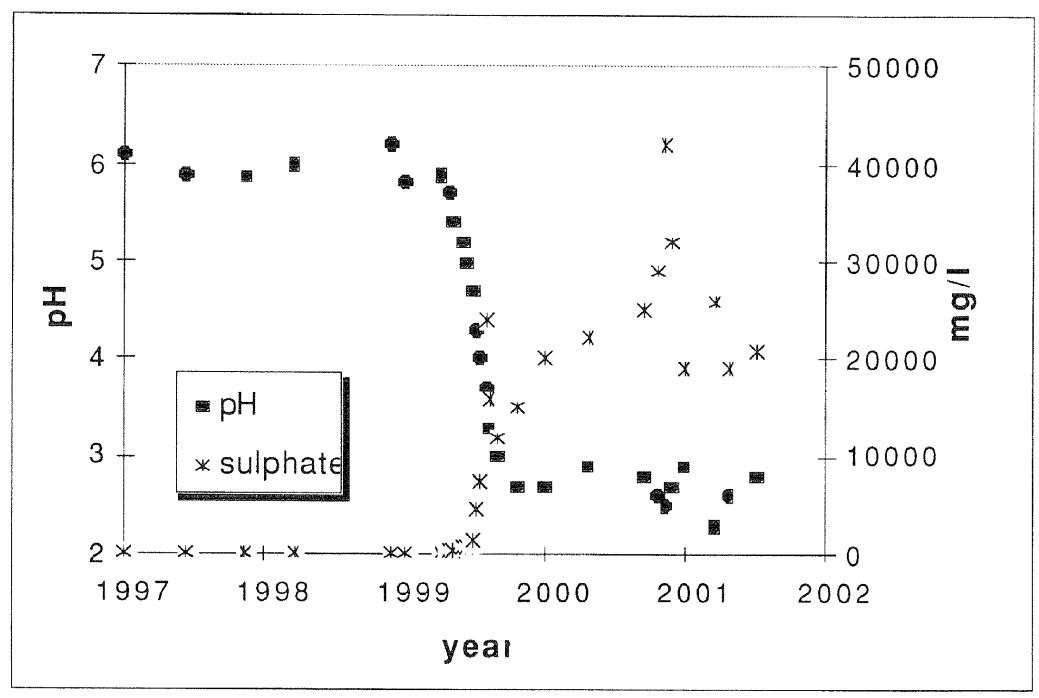

Figure 3: Time dependance of $\mathrm{pH}$ and sulphate concentration in groundwater below the landfill.

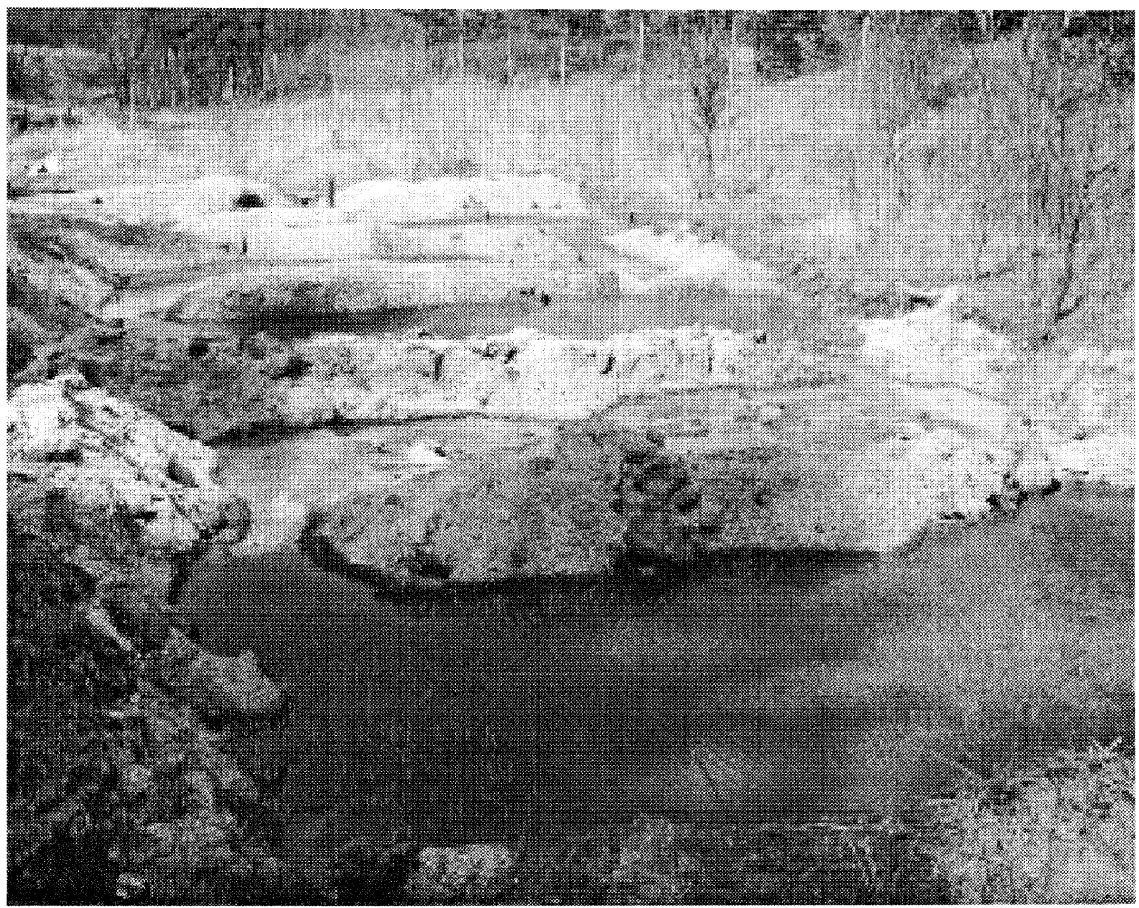

Figure 4: Temporary neutralisation meander (consisting of calcium carbonate) built up across the stream of polluted groundwater after its rising up to the surface. 


\section{Environmental Health Risk}

\section{Methods}

\subsection{Soil sampling}

As noted above, the most serious damage caused by landfill breakdown consisted in complete devastation of higher plants and in affecting soil ecosystem at the area of about $10000 \mathrm{~m}^{2}$. Consequently the following bioassays of soil elutes were provided in this study: test of dehydrogenase activity of soil enzymes, test of inhibition of algal growth and bioassay with higher aquatic plant Lemna minor.

The path of acidic landfill leachate flowing, during its accidental release, on the ground surface could easily be observed even two years after accident, when soil sampling was performed. All the higher vascular plants at the area affected were dead and exhibited dark grey colour. The sampling points used are schematically shown in the Fig. 5. All the points were situated in lower part of the landfill area. Point (A) was placed at the edge of the devastated surface, about 20 meters uphill the neutralisation meander. Point B was situated 10 meters down the meander to be able to assess the neutralisation effect of calcium carbonate. Point $\mathrm{C}$ is an estuary of polluted water flow into small stream, which is situated about $50 \mathrm{~m}$ from lower part of the landfill area. Points D and E were taken $10 \mathrm{~m}$ downstream and 20 meters upstream the estuary. The sample from point $\mathrm{E}$ was considered as uncontaminated as the soil here has never been in contact with leachate.

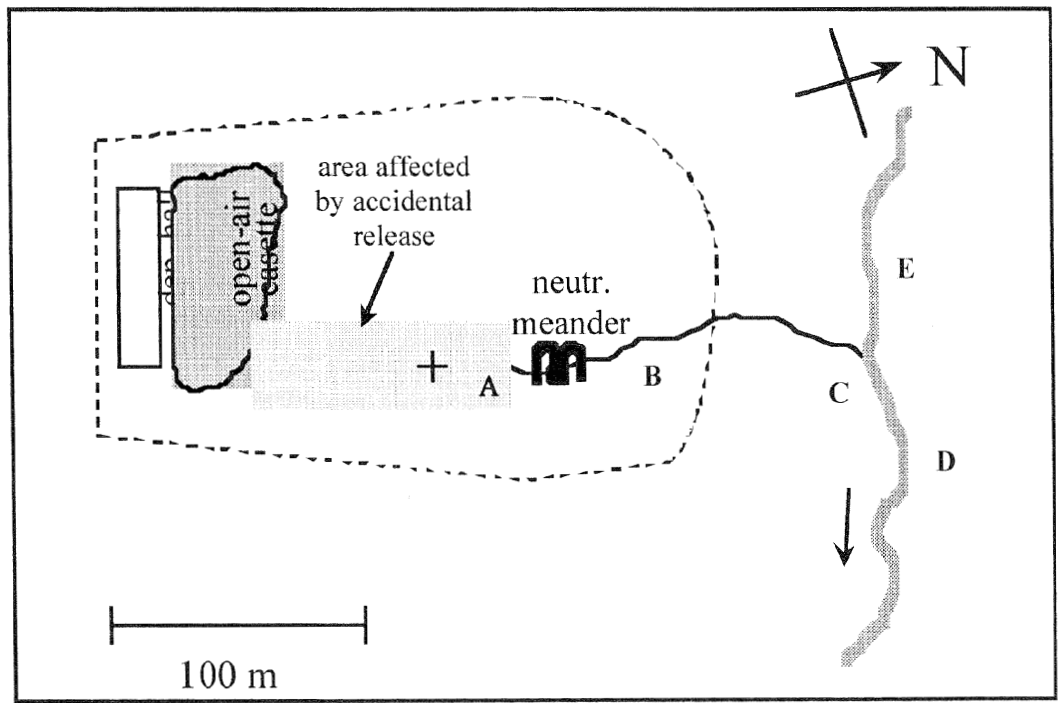

Figure 5: Soil sampling scheme (dotted line represents fencing of the landfill area, cross sign shows a point, where polluted groundwater rises from ground to the surface, letters A - E represent soil sampling points) 


\subsection{Ecotoxicological assays}

\subsubsection{Test on dehydrogenase activity of soil enzymes (DHA)}

This assay represented the overall activity of soil enzymes. The DHA test is a suitable parameter to indicate a degree of damage in soil microbial community. Microbial vitality of soil is determined via natural hydrolytic reactions of terazolium salt reagent (TTC) by means of microbial enzymes. The amount of a hydrolytic product is directly proportional to soil life potential on microbial level. The test procedure was described in detail by Rogers and Li [1].

Soil samples were taken from $20-40 \mathrm{~cm}$ depth. All plant residues were removed before sampling. The soil was air dried at the laboratory temperature and passed through $2 \mathrm{~mm}$ sieve. Standard soil was prepared according to ISO 112681 guideline and it was also air dried and sieved $(2 \mathrm{~mm})$. The standard soil was used for comparative purpose. Enriched standard soil was prepared in the following manner. The standard soil and emerged lucern, Medicago sativa, were mixed to form homogenous mixture (100:1) and deionised water was added to achieve about $20 \%$ of water holding capacity. The water holding capacity was determined according to ISO 11274. This moisture enriched soil was incubated at the laboratory temperature in the dark chamber for 5 days. The enriched soil was used to inoculate the samples and also as a comparative sample.

Each sample as well as a comparative sample $(0.5 \mathrm{~g})$ was mixed in $10 \mathrm{ml}$ test tubes with inoculum $(1 \%)$ and pre-incubated for 24 hours at $25{ }^{\circ} \mathrm{C}$ in the dark chamber. Assay was initiated by adding $0.25 \mathrm{ml}$ of $0.5 \%$ glucose solution $(\mathrm{w} / \mathrm{v})$ and $0.2 \mathrm{ml}$ of $3 \%(\mathrm{w} / \mathrm{v})$ 2,3,5-triphenyl-2H-tetrazolium chloride (TTC) solution. Assay and control tubes were incubated for 24 hours at $27{ }^{\circ} \mathrm{C}$ in the dark chamber. Then $8.00 \mathrm{ml}$ of methanol was added to each tube at the end of incubation and mixtures were thoroughly mixed by shaker to extract TT-formazan formed during the incubation. Absorbance of red solution was measured at 485 $\mathrm{nm}$ after sedimentation of solid phase. The inhibition of DHA was determined by using a following equation:

$$
I=\frac{\left(A_{C}-A_{S}\right)}{A_{C}} 100 \%
$$

Where $A_{C}$ is the comparative solution absorbance at $485 \mathrm{~nm}$ and $A_{S}$ is the sample solution absorbance at the same wavelength. A mixture of methanol (8.00 $\mathrm{ml})$ and deionised water $(0.45 \mathrm{ml})$ was used as a blank.

Sodium hydrogen carbonate was used to adjustment $\mathrm{pH}$, which was determined by ISO 10390 guideline.

\subsubsection{Test of inhibition of algal growth}

The experiments employed Scenedesmus subspicatus, strain BRINKMANN 1953/SAG 86.81 (obtained from the Culture Collection of Autotrophic Organisms, Institute of Botany, Czech Acad. Sci. Třebon). The alga was maintained and cultivated in suspension condition and medium recommended in ISO 8692 guideline. Monospecific algal cells were cultured for several generations in a defined medium containing a range of concentrations of the tested eluate, prepared by mixing appropriate quantities of nutrient concentrate, 


\section{Environmental Health Risk}

demineralised water and an inoculum of exponentially growing algal cells. $10^{4}$ cells per millilitre as initial cell density was used. The test solutions were incubated in microplates for a period of 96 hours, at a light intensity of $60 \mu \mathrm{E} . \mathrm{m}$ ${ }^{2} \cdot \mathrm{s}^{-1}$, fluorescent tubes-day, at $25^{\circ} \mathrm{C}$. The cell density in each suspension was measured, with a microplate reader PowerWave XS (wavelenght $750 \mathrm{~nm}$ ) every 24 hours. Inhibition was measured as a reduction in growth and growth rate relative to control cultures grown under identical conditions (EC50), after $72 \mathrm{~h}$. The test procedure was described in details by Lukavsk_ [2].

\subsubsection{Test on duckweed Lemna minor}

The toxicity to duckweed was determined according to the SIS [3] standard. Three plants of the two floating specie Lemna minor were optically measured for leaf area determination and placed in separate containers with increasing concentration of tested elute. Light was provided by full spectrum grow lamps with an intensity of 2100 lux at the water surface. The light period was $18 \mathrm{~h}$ per day. After a period of 14 days, all plants were harvested and area of leaves were optically measured. Growth of each plant population were calculated according to: $\left(\ln \mathrm{A}_{2}-\ln A_{1}\right) t^{-1}$, where $A_{1}$ and $\mathrm{A}_{2}$ are initial and final area of leaves of a plant in sample and $t$ is incubation time in days. The resulted dose responce curve of inhibition of plant growth caused by increasing concentration of elute/toxicant was used for evaluation.

\section{Results and discussion}

Dehydrogenase activity bioassay shows any presence of soil enzymes. That is because all plant and bacteria communities have died. Algal growth bioassay shows possibility of growing of plants on these sites. That means that all toxic substances passed through area quickly - in soluble form. During the passing through of contaminants all communities have died, probably because of the low $\mathrm{pH}$. If the $\mathrm{pH}$ of soil is increased, no toxic effect on plants occurs. All toxicants have left the area in soluble form and/or were buffered by soil into biologically inactive forms.

All provided bioassay show low toxic effects of presented pollutants on testing organisms. Main adverse effect was caused by low value of $\mathrm{pH}$. When $\mathrm{pH}$ was compensated by a buffering effect of soil no additional toxic response was obtain. The change in $\mathrm{pH}$ value is responsible for changeover of chemical and biological properties of present compounds.

Contaminated soil is after $\mathrm{pH}$ alteration acceptable for microalgae and vascular plants, too. If the source of pollution is eliminated the fast natural attenuation can be expected. The buffering capacity of soil is depleted, so gentle manner of neutralization can be taken into account. No sense of neutralization will be found if the source of pollution will not be eliminated. 
Table 1. The $\mathrm{pH}$ values measured in soil aqueous extracts ( soil $/$ water $=1: 10$ ).

\begin{tabular}{|l|c|}
\hline \multicolumn{1}{|c|}{ Sampling point } & $\mathrm{pH}$ \\
\hline (A) $30 \mathrm{~m}$ uphill the neutralization meander & 4,89 \\
\hline (B) $20 \mathrm{~m}$ downhill the neutralization meander & 3,97 \\
\hline (C) Estuary of surface water into stream & 3,54 \\
\hline (D) $10 \mathrm{~m}$ downstream the estuary & 4,09 \\
\hline (E) $20 \mathrm{~m}$ upstream the estuary & 6,70 \\
\hline
\end{tabular}

Table 2. Inhibition and/or stimulation of dehydrogenase activity of soil enzymes.

\begin{tabular}{|c|c|c|c|}
\hline $\begin{array}{c}\text { Sampling } \\
\text { point }\end{array}$ & \multicolumn{3}{|c|}{ Inhibition of DHA [\%] } \\
\hline & nontreated soil & neutralized soil & $\begin{array}{c}\text { Soil pH altered on } \\
8,5-9\end{array}$ \\
\hline (A) & 87 & -43 & 53 \\
\hline (B) & 82 & -103 & 47 \\
\hline (C) & 88 & -37 & 20 \\
\hline (D) & 89 & -12 & 61 \\
\hline (E) & 1 & - & - \\
\hline
\end{tabular}

Table 3. Bioassay with duckweed Lemna minor.

\begin{tabular}{|c|c|c|c|}
\hline \multirow{3}{*}{$\begin{array}{c}\text { Sampling } \\
\text { point }\end{array}$} & \multicolumn{3}{|c|}{ Growth inhibition of Lemna minor } \\
\cline { 2 - 4 } & \multicolumn{3}{|c|}{ Dilutions } \\
\cline { 2 - 4 } & $\begin{array}{c}62,5 \text { to } 250, \\
\mathrm{~mL} / \mathrm{L}\end{array}$ & 250 to $500, \mathrm{~mL} / \mathrm{L}$ & 500 to $1000, \mathrm{~mL} / \mathrm{L}$ \\
\hline (A) & -80 to $-30 \%$ & -30 to $50 \%$ & 50 to $100 \%$ \\
\hline (B) & -75 to $-10 \%$ & -10 to $45 \%$ & 45 to $85 \%$ \\
\hline (C) & -50 to $-30 \%$ & -30 to $65 \%$ & 65 to $100 \%$ \\
\hline (D) & -50 to $0 \%$ & 0 to $50 \%$ & 50 to $80 \%$ \\
\hline (E) & -10 to $+10 \%$ & 0 to $10 \%$ & 5 to $25 \%$ \\
\hline
\end{tabular}




\section{Environmental Health Risk}

\section{Conclusions}

It follows from the experiments carried out that the main condition of recovery of the affected area is removal of the pollution source to stop further release of acidic leachates to the ground. Three different types of soil ecotoxicological tests were performed using samples taken at the area affected. The main adverse effect observed was caused by low pH. No additional toxic response was obtained after neutralisation. Present state of soil is not acceptable for plant growth, but after effective neutralization the perspective of natural attenuation is good.

\section{Acknowledgements}

Financial support of the Authorized Czech Package Company EKOKOM and of the Grant Agency of the Czech Republic (Grant No 104/02/0663) is gratefully appreciated.

\section{References:}

[1] Rogers, J. E. \& Li, S. W., Effect of Metals and Other Inorganic Ions on Soil Microbial Activity: Soil Dehydrogenase Assay as a Simple Toxicity Test. Bull. Environ. Contam. Toxico, 34, pp. 858-865, 1985.

[2] Lukavský, J., Microprocedure for standard marine algal bioassay (ISO 10253) - Algological Studies, 101, pp. 137-147, 2001.

[3] SIS (Swedish standard institution, Stockholm, Sweden). Water qualityDetermination of growth inhibition (7-d) Lemna minor, duckweed. SS 0282 pp. 13, 1995. 